\title{
Global ozone trends reassessed
}

\section{A new study reported in this issue says that ozone is being depleted globally. But the extent of the depletion is debatable - and has been debated.}

IN a paper on page 219 of this issue, Donald Heath now of the National Oceanic and Atmospheric Administration (NOAA), reports large decreases in global ozone concentrations measured using the Solar Backscatter Ultraviolet (SBUV) instrument on the atmospheric research satellite Nimbus 7 ; the decreases are much larger than expected from theoretical calculations. A working group set up by the National Aeronautics and Space Administration (NASA) has exhaustively studied Heath's data, other ozone measurements and photochemical models of the atmosphere, and will have reported its findings at a press conference in Washington DC this week. The group concludes that there is a serious drift in the calibration of SBUV, but that even after accounting for the drift, the global depletion of ozone is real. In the light of the NASA study, it is clear that Heath's uncorrected trends of global ozone depletion are too large. When the data are corrected for calibration drift, the trends agree reasonably well with current views of how anthropogenic emissions perturb the chemistry of the atmosphere.

Heath's data suggest that there has been a large decrease in global ozone since about 1978 and that an Arctic 'ozone hole' has developed, similar to, but less pronounced than the Antarctic 'ozone hole'. The decreases reported by Heath are considerably larger than those predicted by photochemical models of the effect of chlorofluorocarbons (CFCs) and solarcycle variations on the atmosphere. K.P. Bowman (Science 239, 48-50; 1987) finds trends of similar magnitude using archived data from the Total Ozone Mapping Spectrometer (TOMS) on Nimbus 7.

Heath's report to a Congressional Committee in 1986 of a preliminary version of his findings caused NASA, in collaboration with other agencies, to set up the Ozone Trends Panel for a critical evaluation of all available ozone data.

The discovery of the Antarctic ozone hole was a surprise (see Nature 315, 207; 1985). It had not been predicted by any photochemical model, and there was no immediately obvious explanation for it. The primary importance of the discovery was the realization that if the chemistry of such gross changes is not understood, other subtle yet significant changes going on elsewhere might also have been missed. The SBUV/TOMS trend could have been one of these significant changes, which is why the Ozone Trends Panel (OTP) was set up.

The available reasonably long-term data set examined by the panel includes the surface network of Dobson spectrophotometers, the SBUV and TOMS instruments and the Stratospheric Aerosol and Gas Experiments, SAGE I and SAGE II, on the Applications Explorer Mission-B (1979) and the Earth Radiation Budget Satellite (1984), respectively.

At the outset, the panel found all the ozone data to be unsatisfactory. The archival Dobson data suffer from qualitycontrol problems, such as unrecorded recalibrations of individual instruments. The SBUV and TOMS data suffer from the degradation of their common calibration mechanism, a diffuser plate reflecting solar radiation into the intruments to provide a full-scale measurement. When the study began, the SAGE II meausurements were still being validated, while the SAGE I data had been processed by a different algorithm (and was reprocessed for the panel).

Heath points out a drift of about -0.4 per cent per year of the SBUV total column ozone with respect to the Dobson network. The panel found that by making different, but reasonable, assumptions about the degradation of the diffuser plate, this drift can be eliminated. They conclude that the ozone trend in the archived SBUV data set, as reported by Heath, is overestimated, and that the uncertainties are larger than that stated by the data-processing team.

A significant fraction of the Dobson data was re-analysed for the panel, taking into account instrument calibration changes and station reliability. These data do not give global coverage, but are believed to reliable, and have been used to renormalize the TOMS and SBUV data by guiding the selection of a diffuser degradation model. The renormalized TOMS data show a global decrease of 2.6 per cent from November 1978 to October 1985. After 1985, there is a hint of an increase in the Northern Hemisphere, but depletion continues in the Southern Hemisphere with negligible global change.

Model calculations to include the effects of CFCs and solar-cycle variations were carried out for the panel by four different research groups. They show that the solar cycle should have had a comparable or greater effect on total ozone than that of the trace gases over the period
1979-85. Calculated changes are broadly consistent with the observations in the Northern Hemisphere, but not in the Southern Hemisphere, perhaps because the (unmodelled) Antarctic ozone hole is offsetting the solar-cycle effect throughout the Southern Hemisphere.

For the period up to the next solar maximum, the OTP predicts that the increase in ozone resulting from increased solar ultraviolet radiation will mask or even reverse the decrease caused by increasing concentrations of CFCs. This implies that, after the solar maximum, the decrease will continue with renewed vigour.

Data from SAGE I and SAGE II during the period 1979-85 show a maximum depletion of about 3 per cent in ozone density at an altitude of $40 \mathrm{~km}$, with no change at $50 \mathrm{~km}$. A re-analysis of the SBUV vertical profile data, using the diffuser plate model that eliminates the bias between SBUV and Dobson data, brings the profile trend into better agreement with the model calculations. For the same period as SAGE, the maximum depletion is around 7 per cent at $40 \mathrm{~km}$, decreasing to near zero at $50 \mathrm{~km}$.

The model calculations all show maximum global depletion around $40 \mathrm{~km}$, varying from 5 to 12 per cent for different models. Of this, 4-9 per cent is response to CFCs, and 1-3 per cent is the response to reduced solar ultraviolet output approaching the solar minimum.

Important indirect support for the photochemical models can be found in stratospheric temperature trends. It seems that the photochemical models and the latest measurements of atmospheric ozone trends are beginning to converge, and are giving broad agreement globally, although the Antarctic ozone hole is still not well-enough understood to be included in models. The error bars for both measurements and models are still large, but quantitative evidence for the effects of CFCs on ozone in the atmosphere is now much more convincing. The processing and release for study of the data from the SBUV-2, launched in 1984 by NOAA on an operational meteorological satellite, are eagerly awaited. These data should settle any remaining doubts about what is really happening to the ozone layer on the global scale.

Clive Rodgers

Clive Rodgers is a member of the Ozone Trends Panel and is at the Department of Atmospheric Physics, Oxford University, Clarendon Laboratory, Parks Road, Oxford OXI $3 P U, U K$. 